Tropical Journal of Pharmaceutical Research April 2012; 11 (2): 297-305

(c) Pharmacotherapy Group,

Faculty of Pharmacy, University of Benin, Benin City, 300001 Nigeria.

All rights reserved.

Available online at http://www.tjpr.org

Research Article

http://dx.doi.org/10.4314/tjpr.v11i2.18

\title{
Antihypertensive Drug Prescribing in a Tertiary Hospital in Eastern Nigeria
}

\section{Chinwe V Ukwe and Chukwuemeka M Ubaka}

Department of Clinical Pharmacy and Pharmacy Management, Faculty of Pharmaceutical Sciences, University of Nigeria, Nsukka 410001, Nigeria

\begin{abstract}
Purpose: To determine the pattern of antihypertensive medication prescription in a referral hospital in Nigeria and its use by patients.

Methods: By method of convenience sampling, 4954 prescriptions were collected from 376 files of hypertensive patients (> 18 years) visiting a referral hospital in Enugu, southeastern Nigeria between June and July 2009, were retrospectively surveyed. Data on visits, antihypertensive medication, nonantihypertensive medication and drug adverse effects were extracted, coded and analyzed.

Results: The mean age of hypertensive patients was 61 years, and an almost equal number of females (49 \%) and males (51\%) visited the hospital. The average number of antihypertensive drug per patient was $2.63 \pm 0.92$ and $90 \%$ of the patients were prescribed more than one drug in their last visit. For individual antihypertensive drugs, hydrochlorothiazide (29.7\%) and lisinopril (20.3\%) were the most prescribed with low-dose aspirin (39.7\%) and non-steroidal anti-inflammatory agents (16.7\%) occurring as most co-prescribed medication. Adverse effects were reported by $11 \%$ of the patients while $18 \%$ of the patients were non-adherent.

Conclusion: The study showed a high use of more than one drug as supported by applicable guidelines hypertension, with diuretics and angiotensin converting enzyme inhibitors ACEls the being most prescribed probably due to their low-cost and observed efficacy in this setting.
\end{abstract}

Keywords: Antihypertensives, Prescribing, Referral, Drug utilization, Nigeria

*Corresponding author: Email: pharmubk@yahoo.com; Tel: +234 8038246913 


\section{INTRODUCTION}

Hypertension is a frequently encountered chronic medical condition and is one of the most significant risk factors for cardiovascular morbidity and mortality. Developing economies struggle to maintain a qualitative health care sector and usually find it difficult keeping up with international standards of medical care. Hypertension management is for life and antihypertensive medications are relatively expensive. A report of the Joint National Committee on Prevention, Detection, Evaluation, and Treatment of High Blood Pressure was released in 2003 and was considered a gold standard for hypertension management [1]. The report among other things, advocates that a majority of patients will require two medications to reach goal blood pressure and thiazides for most of the stage 1 hypertension [1]. In the treatment of hypertension, however, an individualized stepped care therapy has been advocated for specific patients on the basis of differences in race, age, co-morbidity, adverse effects, adherence to treatment, etc, to improve cardiovascular outcomes [2]. Some studies support the use of calcium channel blockers and diuretics in the elderly and blacks and angiotensin converting enzyme inhibitors (ACEIs) and beta blockers in the young and Caucasians [3]. Combination therapy using antihypertensive drugs of different mechanisms of action has been used to produce optimal control of blood pressure where monotherapy fails [1].

Various studies have been carried out on the utilization of antihypertensives in different regions of Nigeria [4,5]. However little or no information is available on antihypertensive usage in southeastern region of Nigeria, which is a densely populated part of the country. This study was aimed at evaluating the pattern of antihypertensive drug prescribing in a referral hospital in the southeastern part of Nigeria.

\section{METHODS}

This was a descriptive retrospective survey, cross-sectional in nature and carried out between the months of June and July 2009. The cardiovascular (medical) outpatient clinic of the University of Nigeria Teaching Hospital in Enugu, Enugu State was used for the survey. The facility is owned and funded by the Federal Government of Nigeria, with over 500 beds in 41 departments and clinics. It is a referral center (especially for cardiovascular diseases) for neighbouring states, especially in the southeastern part of Nigeria. The hospital has a mission to provide quality training, research and specialist healthcare for its clients in a friendly environment, and particularly pursues excellence in cardiovascular care.

A data collection form was developed to collect information from patient's prescriptions. It was pre-tested prior to the start of the study, using 20 randomly selected files which were not included in the final study. Necessary adjustments were made to the form. Ethical clearance for the study was granted by the University of Nigeria Teaching Hospital Research Ethics Committee and patients' information was kept confidential. Folder numbers of visiting patients who were diagnosed and/or treated for hypertension for at least six months were collected from the clinic registers. Also only files with referral notes or orders were selected in order to note the first visit of the patient to the hospital. However, due to a high incidence of missing and temporary files, a convenience sampling method was employed. Four hundred files were sampled and twenty four files were removed because of incompleteness in prescription and prescription information. Three hundred and seventy six (376) files were used and data on patients' characteristics, other co-existing diseases, number of prescriptions, prescription details on antihypertensive and non-hypertensive medication, level of patient's medication adherence and adverse drug effects as documented by physicians, were collected. 
These data were coded into Microsoft Excel 2007, crosschecked for consistency, then entered into Statistical Package for Social Sciences application (SPSS Inc, version 14, Chicago, USA) and analyzed using descriptive frequencies of mean and percentages. Patient characteristics and prescription details were compared using analysis of variance and $x^{2}$ test for continuous and categorical variables, respectively. Spearman's rank correlation coefficient was used to measure correlations between variables, and independent predictors were identified with multiple linear regression. $P$ values $<0.05$ were considered statistically significant in all cases.

\section{RESULTS}

A total of 4954 prescriptions were collected from the 376 patients' files that were conveniently sampled. Patient characteristics are displayed in Table 1.

Table 1: Characteristics of hypertensive adults visiting a Nigerian referral hospital

\begin{tabular}{lcc}
\hline Characteristics & $\mathbf{N}^{*}$ & $\%$ \\
\hline Age, mean (SD) & $61(11.8)$ & \\
Age range & $18-90$ & \\
Age group & & \\
18-49 & 53 & $(14.1)$ \\
$50-90$ & 323 & $(85.9)$ \\
Sex & & \\
Male & 192 & 51.1 \\
Female & 184 & 48.9 \\
Marital Status & & \\
Married & 338 & 89.89 \\
Single & 17 & 4.52 \\
Widowed & 21 & 5.59 \\
Occupation & & \\
Civil servant & 80 & 21.27 \\
House wife & 91 & 24.20 \\
Pensioner & 21 & 5.58 \\
Skilled worker & 52 & 13.82 \\
Unskilled worker & 99 & 26.32 \\
Retired & 24 & 6.38 \\
Unemployed & 4 & 1.06 \\
No records & 5 & 1.33 \\
Total & 376 & 100.00 \\
\hline
\end{tabular}

${ }^{*} N=$ number of patients; $S D=$ standard deviation.

\section{Co-existing diseases and blood pressure levels during visit}

Of all the patients, 267 (71\%) were codiagnosed with one form of cardiovascular disease or chronic ailment. Diabetes ranked as the most frequent co-morbidity $(n=77,19.7$ $\%$ ) followed by hypertensive heart disease ( $\mathrm{n}$ $=56,14.3 \%$ ), as indicated in Table 2. There were also a high number of patients who had suffered cerebrovascular accident $(n=43,11$ $\%)$ and peptic ulcer $(n=57,14.6 \%)$. The average systolic (SBP) and diastolic blood pressures (DBP) of patients during first and last visits are shown in Table 2. The mean SBP/DBP in the first visit of patient was 163.0 $\pm 24.2 / 99.0 \pm 15.8 \mathrm{mmHg}$ (mean \pm SD) and in the last visit was $141.0 \pm 23.3 / 87.0 \pm 15.1$ $\mathrm{mmHg}(P<0.05)$. Also displayed in Table 2, is the distribution of blood pressure levels among patients using the JNC 7 report [1]. From the first to the last visits, there was a significant change in the number of patients with normal blood pressure, prehypertension, stage 2 hypertension, and isolated diastolic hypertension (IDH).

Class of hypertension by blood pressure measurement showed positive correlation with number of drugs in the last prescription $(p<0.001)$ but no correlations were seen with age, sex or number of comorbidities. Multiple regression showed that the only number of drugs in the last prescription $(\beta=0.252, \quad P=0.001)$ was an independent predictor of $\mathrm{BP}$ at the last visit $(R=0.284, p<$ 0.001).

\section{Number of antihypertensive drugs}

From the collected prescriptions, a total of 12,079 antihypertensive medications were prescribed to all the patients from their first visit to the study date. The frequency of antihypertensive agents prescribed to patients in their first and last visits before the study, are presented in Table 3. The average number of drugs prescribed per patient in the first and last prescriptions was $2.25 \pm 0.77$ 
Table 2: Patients' blood pressure distribution (by class) and co-morbidities at the first and last visits of the study period

\begin{tabular}{|c|c|c|}
\hline Blood Pressure & First visit & Last visit \\
\hline Average (SD) & $\mathbf{N}(\%)$ & $\mathbf{N}(\%)$ \\
\hline Systolic BP (mmHg) & $163(14.2)$ & $141(23.3)^{\star}$ \\
\hline Diastolic BP (mmHg) & $99(15.8)$ & $87(15.1)^{*}$ \\
\hline \multicolumn{3}{|c|}{ Class } \\
\hline Normal & $13(3.50)$ & $71(18.90)^{*}$ \\
\hline Prehypertension & $42(11.20)$ & $145(38.60)^{*}$ \\
\hline Stage 1 & $46(12.20)$ & $43(11.40)$ \\
\hline Stage 2 & $171(45.50)$ & $58(15.40)^{*}$ \\
\hline Isolated Systolic & $46(12.20)$ & $43(11.40)$ \\
\hline Hypertension & & \\
\hline $\begin{array}{l}\text { Isolated Diastolic } \\
\text { Hypertension }\end{array}$ & $51(13.60)$ & $14(3.70)^{*}$ \\
\hline Nil record & $7(1.90)$ & $2(0.50)^{*}$ \\
\hline Total & 376 & 376 \\
\hline Co-morbidities & $\mathbf{N}$ & $\%$ \\
\hline $\begin{array}{l}\text { Hypertensive heart } \\
\text { disease }\end{array}$ & 56 & 14.35 \\
\hline Diabetes & 77 & 19.74 \\
\hline $\begin{array}{l}\text { Cerebrovascular } \\
\text { accident }\end{array}$ & 43 & 11.02 \\
\hline $\begin{array}{l}\text { Left ventricular } \\
\text { failure }\end{array}$ & 20 & 5.13 \\
\hline Dyslipidemia & 6 & 1.54 \\
\hline Angina Pectoris & 10 & 2.56 \\
\hline \multicolumn{3}{|l|}{$\begin{array}{l}\text { Other co-existing } \\
\text { diseases }\end{array}$} \\
\hline Arthtritis & 45 & 11.54 \\
\hline Peptic ulcer & 57 & 14.6 \\
\hline Seizures & 16 & 4.10 \\
\hline Obesity & 19 & 4.87 \\
\hline Asthma & 13 & 3.33 \\
\hline Others & 28 & 7.15 \\
\hline Total & 390 & 100 \\
\hline
\end{tabular}

$B P$ values are shown as mean $(S D) ;{ }^{*}$ represents changes at $p<0.05$, one-way analysis of variance. $N$ represents the number of patients with the particular disease or blood pressure class

and $2.63 \pm 0.93$, respectively. There was a reduction in the number of patients on one drug between the first and the last visit (104 to 35), and two drugs (184 to 144) but an increase in patients receiving three drugs (77 to 130), four drugs (11 to 59) and five drugs (0 to 8$)$. All these changes were significant at $p<0.001$. Ninety percent $(90 \%)$ of patients were prescribed more than one drug in their last visit. Correlation results show positive correlations and predictor ability of average number of drugs $(R=0.783, p<0.001)$ taken by the patients with class of age $(\beta=0.232, p$ $=0.001)$ and maximum number $(\beta=0.565, p$ $<0.001$ ) of drugs taken in a single prescription.

\section{Commonly used antihypertensive drugs}

Table 3 presents the number of patients that were prescribed specific antihypertensive drugs at the first and last visits; there was a high rate of use of hydrochlorothiazide (27.7 and $29.7 \%$, respectively), lisinopril (14.2 and $20.3 \%$, respectively) and nifedipine (12.3 and $11.3 \%$, respectively). There was a high use rate of benzodiazepines for the treatment of hypertension only at the first visit $(2.7 \%)$.

Use by class (Figure 1) shows a high use rate of diuretics at the first and last visits (48.2 and $46.4 \%$, respectively), ACEls/angiotensin receptor blockers (ARBs) (18.2 and $25.6 \%$, respectively) and calcium channel blockers (CCBs) (15.1 and $15.9 \%$, respectively) with the use of $A C E I / A R B$ increasing significantly $(p<0.05)$.

\section{Non-pharmacological management}

Based on physicians' documentation, a majority (268, i.e., $71 \%$ ) received nonpharmacological counsel while the remaining (108, i.e., $29 \%$ ) did not. Specifically, salt restriction $(n=118,31.3 \%)$, diet therapy $(n=$ $76,20.2 \%)$ and weight reduction $(n=102$, $27.1 \%$ ) were the most frequent nonpharmacological advice. Other documented counsel include physiotherapy $(8.3 \%)$ and stress reduction (1.2\%).

\section{Co-prescribed medication}

About $40 \%(n=147)$ of the patients were placed on low-dose (75 mg) aspirin and about 11 (3\%) on statins. With about $19 \%$ of the patients diabetic, only 30 (8\%) were on antidiabetics. Also, over $16 \%(n=62)$ of 
Ukwe et al

Table 3: Frequency of antihypertensive medication prescribed in the first and last prescriptions

\begin{tabular}{|c|c|c|c|c|}
\hline \multirow[b]{2}{*}{ Antihypertensive drug } & \multicolumn{2}{|c|}{ First visit } & \multicolumn{2}{|c|}{ Last visit } \\
\hline & $\mathbf{N}^{*}$ & $\%$ & $\mathbf{N}^{*}$ & $\%$ \\
\hline \multicolumn{5}{|l|}{ Diuretics } \\
\hline Amiloride & 98 & 11.54 & 73 & 7.38 \\
\hline Hydrochlorothiazide & 236 & 27.7 & 294 & 29.72 \\
\hline Chlorthalidone & 8 & 0.94 & 9 & 0.91 \\
\hline Frusemide & 37 & 4.35 & 36 & 3.64 \\
\hline Spironolactone & 30 & 3.53 & 43 & 4.34 \\
\hline \multicolumn{5}{|c|}{ Calcium channel blockers } \\
\hline Amlodipine & 15 & 1.76 & 24 & 2.42 \\
\hline Felodipine & 8 & 0.94 & 17 & 1.71 \\
\hline Nifedipine & 105 & 12.36 & 117 & 11.38 \\
\hline \multicolumn{5}{|l|}{ Beta blockers } \\
\hline Propanolol & 17 & 2.00 & 14 & 1.41 \\
\hline Atenolol & 9 & 1.06 & 11 & 1.11 \\
\hline Metoprolol & - & - & 1 & 0.1 \\
\hline \multicolumn{5}{|c|}{ Angiotensin converting enzyme inhibitors } \\
\hline Lisinopril & 121 & 14.25 & 201 & 20.32 \\
\hline Enalapril & 16 & 1.88 & 30 & 3.03 \\
\hline Ramipril & 16 & 1.88 & 13 & 1.31 \\
\hline Captopril & 1 & 0.11 & - & - \\
\hline \multicolumn{5}{|c|}{ Angiotensin receptor blockers } \\
\hline Losartan & - & - & 5 & 0.5 \\
\hline Valsartan & 1 & 0.11 & 5 & 0.5 \\
\hline \multicolumn{5}{|l|}{ Miscellaneous drugs } \\
\hline Hydralazine & 11 & 1.29 & 3 & 0.3 \\
\hline Methyldopa & 64 & 7.53 & 86 & 8.69 \\
\hline Reserpine & 29 & 3.41 & 2 & 0.2 \\
\hline Prazocin & 1 & 0.11 & 4 & 0.4 \\
\hline Intravenous fluids & 3 & 0.35 & - & - \\
\hline Benzodiazepine & 23 & 2.71 & 1 & 0.1 \\
\hline Total & 849 & 100 & 989 & 100 \\
\hline
\end{tabular}

${ }^{*} \boldsymbol{N}$ represents the number of patients prescribed the particular drug. Percentage was calculated per total of number drugs in that visit.

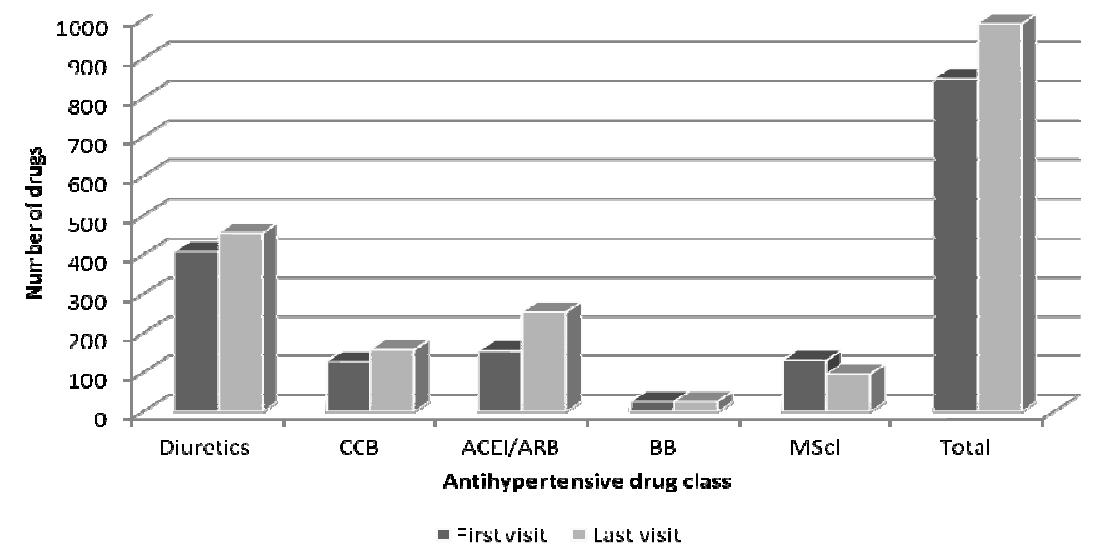

Figure 1: Prescription of antihypertensive drugs by class to patients during their first and last visits. Note: $\mathrm{CCB}=$ Calcium Channel Blockers, $\mathrm{ACEl} / \mathrm{ARB}=$ Angiotensin Converting Enzyme Inhibitors/Angiotensin Receptor Blockers, $\mathrm{BB}=$ Beta Blockers, $\mathrm{MSCl}=$ Miscellaneous drugs) 
the patients were on NSAIDs with only 41 $(11 \%)$ of them reported to be suffering from an arthritic condition.

\section{Adverse effects and adherence to medication}

In the patient files, physicians documented complaints of adverse effects and the implicating medications. Among the patients, $43(11.4 \%)$ complained of an adverse effect with cough ( $n=25,58 \%)$, headache $(n=5$, $11.6 \%)$ and rashes $(\mathrm{n}=5,11.6 \%)$ constituting the most common ones. Lisinopril $(\mathrm{n}=25,58 \%)$ and nifedipine $(\mathrm{n}=7,16 \%)$ were the drugs most implicated for causing the adverse effects. Of the 376 patients on antihypertensive agents, 70 (18\%) were recorded by their physicians to be poor or non-adherent to their medications. When an attempt was made to correlate medication adherence with patients' characteristics, sex and blood pressure taken at last visit, showed statistically significant difference (at $p=0.009$ and $p=0.002$ ) between the adherent and non-adherent groups. There were more females in the non-adherent group than in the adherent group (23.9\% vs $13.5 \% ; p=$ 0.009).

\section{DISCUSSION}

This study examined the pattern of antihypertensive drug prescriptions in a tertiary hospital in Eastern Nigeria in order to obtain an insight into the current utilization of antihypertensive drugs. Some limitations of this study include the fact that the hospital used may not be representative of other hospitals in the southeastern region of Nigeria which are much smaller in size and lack the high calibre healthcare expertise available in the health facility used in the present study. Also due to the retrospective nature of this study, some clinical information (for example, on non-pharmacological advice and compliance) could not be retrieved from the physicians and patients and this may affect the validity of the adherence information obtained from patients' files.
It has been established that advancing age is a risk factor for cardiovascular risk diseases [1] and our sample had a larger proportion of older adults, an age group where the incidence of hypertension increases with age. Diabetes, hypertensive heart disease and cerebrovascular accident (CVA) were the most co-diagnosed diseases and their high incidence will alter treatment regimen and achievement of optimal blood pressure in these patients. The observation that more patients had one form of co-existing chronic disease is consistent with the fact that the higher systolic blood pressure (prevalent in this study sample) is associated with increased risk of cardiovascular diseases [1]. The high incidence of CVA in the prehypertensive class has been reported in the current JNC 7 report and could be attributed to non-awareness of this slightly abnormal blood pressure levels by most people and its tendency (i.e., non-awareness) to increase the progression of complications of hypertension. The increase in the number of antihypertensive drugs prescribed to patients at the last visit from the time of first visit may be a reflection of worsening of the high blood pressure condition, increase in the intensity of treatment or prescriber's awareness of the benefits of the use of more drugs to improve management of the disease.

The results from this study show that the use of combination therapy was higher than those recorded in similar studies conducted in southwestern and northern regions of Nigeria $[6,7]$. Older adults took more drugs than the younger group, a possible reflection of an urgent need by physicians to critically control blood pressure in this special group with higher systolic blood pressure values and risk for cardiovascular diseases. In the first visit, the use of hydrochlorothiazide and lisinopril was highest and could be attributed to the advocated use of hydrochlorothiazide both as a monotherapy and as an adjunct in antihypertensive combination therapy [1]. Diuretics are said to be superior to $\alpha$ blockers, CCBs, and ACEls in preventing one 
or more forms of CVDs, including stroke and heart failure [3] and its low cost gives it further advantage. The high use of lisinopril despite reported claims of its average efficacy among blacks and the elderly is probably due to its proven benefits in cardiovascular protection [8], and renoprotection [9]. Diuretics use (by class) was the highest in this study and may be attributed to its low cost, efficacy in blacks and synergistic effect when used in combination with other potent antihypertensive agents [1]. ACEIs/ARBs also remained favorites for prescribers in this study due perhaps to their documented benefits in hypertensives suffering some other diseases (such as diabetes) and their increased efficacy in blacks when used in combination with diuretics [10]. A study in Ibadan, Nigeria [6] reported a lower use of ACEls $(8.6 \%)$ in its cohorts and this marked difference with results in this study may be due to differences in prescriber characteristics. The prescribing of benzodiazepines alone to patients diagnosed as "hypertensive" has not been justified in reducing blood pressure in clinical hypertension [11]. A majority of the sedatives may have been prescribed as anxiolytics to calm anxious patients.

Several studies have documented the longterm benefits of the use of anti-hypertensive combinations in high-risk populations, such as blacks, who are usually at increased risk of morbidity and mortality from cerebrovascular and cardiovascular events [12]. Furthermore, black hypertensives have higher incidences of concurrent diseases such as left ventricular hypertrophy, congestive cardiac failure, diabetes mellitus and chronic renal failure and have been shown to benefit from the use of antihypertensive drug combinations [6]. The most prescribed antihypertensive combination in this study was lisinopril+hydrochlrothaizide at both visits and it has been shown that addition of a low-dose diuretic to lisinopril can achieve blood pressure control in $80-90 \%$ of black patients [10].
The use of low-dose aspirin was high in this population and may provide some benefits for patients with cardiovascular complications. With less than half of diabetics placed on pharmacological treatment and a relative few on diet therapy, about half of them were untreated for diabetes. No reason could not be given for this untreated group of diabetics but high cost of antidiabetics may have been responsible. The high prescription rate of NSAIDs in these patients is worrisome, and the concomitant use of antiulcerogenic agents and antacids could have been responsible for NSAID- induced ulcers while on therapy. Statins been shown to have beneficial effects in secondary prevention of cardiovascular events and its use in this population interestingly was still low and inadequate.

The combined high prescription rate of exercise, reduction of fat intake and weight reduction may be attributed to a large number of obese and overweight patients, a reflection of results from other studies [14], and the well-known efficacy of salt restriction in reducing blood pressure in hypertensive patients, blacks in particularly [2].

Over $11.0 \%$ of patients complained of adverse effects and this finding is similar to those of earlier studies which reported a frequency of 11.0 and $10.9 \%$, respectively $[6,15]$ among hypertensive patients in a similar study setting. This may not be reflective of the true occurrence of adverse reactions in these patients, as poorly institutionalized adverse drug reaction reporting system limits proper documentation of adverse reactions in the health care setting. Lisinopril caused most of these side effects and the irritating cough produced has been well documented as well as noted in some other works as a major reason for poor compliance and discontinuation of ACEls [16]. These complaints of adverse effects by patients as documented by physicians may be lower than actual events and can only be effectively evaluated if a well-organized 
adverse drug reaction monitoring system were in place in this setting.

Medication adherence as recorded by patients' physicians has been used reliably in another Nigerian study and the result obtained in this study is similar to those obtained in the southwestern Nigeria study which reported inadequate adherence in only $17.5 \%$ of its cohort [17]. More females did not adhere to their medications, but no concrete rationale could be raised concerning this as more females attained lower blood pressure than their male counterparts. However, women have been known to be at higher risk of ACEl-induced adverse effects than men and therefore may exhibit higher rates of discontinuation [18].

\section{CONCLUSION}

This study has shown that hypertension in this tertiary hospital is being treated with more than one drug in most patients especially in the elderly. Lisinopril and hydrochlorothiazide were most prescribed drugs and there is increasing trend of prescribing ACEls, diuretics and fixed-dose combination formulations.

\section{ACKNOWLEDGEMENT}

The authors wish to thank the medical and technical staff of the Outpatient Medical Clinics and Records Unit for their technical support during the study.

\section{REFERENCES}

1. Chobanian AV, Bakris GL, Black HR, Cushman WC, Green LA, Izzo JL, et al and the National High Blood Pressure Education Program Coordinating Committee. Seventh Report of The Joint National Committee On Prevention, Detection, Evaluation, And Treatment Of High Blood Pressure. The JNC 7 Report. JAMA 2003; 289: 2560-2572.

2. Aguwa CN. Hypertension. In: Aguwa CN (Ed). Therapeutic Basis of Clinical Pharmacy in the Tropics. $3^{\text {rd }}$ ed. Enugu. Snaap Press. 2004; pp 102-139.

3. The ALLHAT Officers and Coordinators for the ALLHAT Collaborative Research Group. Major outcomes in high-risk hypertensive patients randomized to angiotensin-converting enzyme inhibitor or calcium channel blocker vs. diuretic: the Antihypertensive and LipidLowering Treatment to Prevent Heart Attack Trial (ALLHAT). JAMA 2002; 288: 2981-2997.

4. Erhun WO, Olayiwola G, Agbani EO, Omotosho NS. Prevalence of hypertension in a University Community in South-West Nigeria. Afr $J$ Biomed Res 2005; 8: 15-19.

5. Cooper RS, Rotimi RN, Kaufman JS, Muna WFT, Mensah GA. Hypertension treatment and control in sub-Sahara Africa: the epidemiological basis for policy. BMJ 1998; 316: 614-617.

6. Yusuff KB, Balogun O. Physician's prescribing of antihypertensive combinations in a tertiary care setting in southwestern Nigeria. J Pharm Pharm Sci 2005; 8(2): 235-242.

7. Isezuo AS, Njoku CH. Blood pressure control among hypertensives managed in a specialized health care setting in Nigeria. Afr J Med Med Sci 2003; 32: 65-70.

8. Yusuf S, Sleight $P$, Pogue J, Bosch J, Davies $R$, Dagenais $G$. Effects of an angiotensinconverting-enzyme inhibitor, ramipril, on cardiovascular events in high-risk patients. The heart outcomes prevention evaluation study investigators. N Engl J Med 2000; 14553.

9. Hansson L, Lindholm LH, Niskanen L, Lanke J, Hedner T, Nikalson A, Luomanmaki K, Dahlof $B$, de Faire $U$, Morlin $C$ et al. Effect of angiotensin converting enzyme inhibition compared with conventional morbidity and mortality in hypertension: the Captopril Prevention Project (CAPPP) randomized trial. Lancet 1999; 353: 611-616.

10. Douglas JG, Agodoa L. ACE inhibition is effective and renoprotective in hypertensive nephrosclerosis: the African American Study of Kidney Disease and Hypertension (AASK) trial. Kidney Int Suppl 2003; 83: S74-S76.

11. Olubodun JOB. Physicians" approach to the management of hypertension in a developing community. Int J Cardiol 1995; 51 (2): 193197.

12. Kadiri $S$, Olutade $B O$, Osobamiro $O$. Factors influencing the development of malignant hypertension in Nigeria. J Hum Hypertens 2000; 14: 171-174.

13. Fenves $A$, Ram CV. Are angiotensin converting enzyme inhibitors and angiotensin receptor blockers becoming the treatment of choice in African-Americans? Curr Hypertens Rep 2002; 4 (4): 286-289.

14. Cooper R, Rotimi C. Hypertension in blacks. Am J Hypertens 1997; 10: 804-812.

15. Adigun $A Q$, Ishola $D A$, Akintomide $A O$, Ajayi $A A$. Shifting trends in pharmacologic treatment of hypertension in a Nigerian tertiary hospital: a real world evaluation of the efficacy, safety, rationality and pharmacoeconomics of old and 
new anti-hypertensive drugs. J Hum Hypertens 2003; 17: 277-285.

16. Krumholz HM, Vaccarino V, Ellerbeck EF, Kiefe $C$, Hennen J, Kresowik TF, Gold JA, Jencks SF, Radford MJ. Determinants of appropriate use of angiotensin-converting enzyme inhibitors after acute myocardial infarction in persons > or $=65$ years of age. Am J Cardiol 1997; 581 586 .

17. Yusuff $K B$, Balogun $O B$. Pattern of drug utilization among hypertensives in a Nigerian teaching hospital. Pharmacoepidemiol Drug Saf. 2005; 14: 69-74.

18. Shah MR, Granger CB, Bart BA, McMurray JJ, Petrie MC, Michelson EL, Swedberg K, Stevenson LW, Califf RM, Pfeffer MA. Sex-related differences in the use and adverse effects of angiotensin-converting enzyme inhibitors in heart failure: the study of patients intolerant of converting enzyme inhibitors registry. $\mathrm{Am} \mathrm{J}$ Med 2000; 109: 489-492. 